\title{
Does commitment to rehabilitation influence clinical outcome of total hip resurfacing arthroplasty?
}

\author{
David R Marker ${ }^{1}$, Thorsten M Seyler², Anil Bhave ${ }^{3}$ Michael G Zywiel ${ }^{1}$, Michael A Mont ${ }^{1 *}$
}

\begin{abstract}
Background: The purpose of this study was to evaluate whether compliance and rehabilitative efforts were predictors of early clinical outcome of total hip resurfacing arthroplasty.

Methods: A cross-sectional survey was utilized to collect information from 147 resurfacing patients, who were operated on by a single surgeon, regarding their level of commitment to rehabilitation following surgery. Patients were followed for a mean of 52 months (range, 24 to 90 months). Clinical outcomes and functional capabilities were assessed utilizing the Harris hip objective rating system, the SF-12 Health Survey, and an eleven-point satisfaction score. A linear regression analysis was used to determine whether there was any correlation between the rehabilitation commitment scores and any of the outcome measures, and a multivariate regression model was used to control for potentially confounding factors.

Results: Overall, an increased level of commitment to rehabilitation was positively correlated with each of the following outcome measures: SF-12 Mental Component Score, SF-12 Physical Component Score, Harris Hip score, and satisfaction scores. These correlations remained statistically significant in the multivariate regression model.

Conclusions: Patients who were more committed to their therapy after hip resurfacing returned to higher levels of functionality and were more satisfied following their surgery.
\end{abstract}

\section{Background}

By 2030, the demand for primary total hip arthroplasties is estimated to grow by $174 \%$ to 572,000 [1]. The main goal of total hip arthroplasty is to relieve pain and to improve the functional capacity of the patient. Improved functional results lead to a reduced dependence and improved quality of life. Some of the activities of daily living that are affected by arthritis and need to be focused upon after hip arthroplasty include: climbing stairs, shopping, rising out of a chair or bed, housecleaning, washing, and dressing oneself [2]. A large number of these patients will require a major commitment to rehabilitative efforts to attain these functional abilities.

Hip resurfacing arthroplasty has been recommended by some authors as an appropriate treatment modality for certain patients with end-stage degenerative disease

\footnotetext{
* Correspondence: mmont@lifebridgehealth.org

${ }^{1}$ Center for Joint Preservation and Replacement, Rubin Institute for

Advanced Orthopedics, Sinai Hospital of Baltimore, Baltimore, Maryland, USA
}

of the joint, especially those who are below 65 years of age, have good bone quality, desire to return to a highactivity lifestyles, and have no known metal hypersensitivity $[3,4]$. Some recent studies have shown that hip resurfacing arthroplasty allows patients to have improved function and reduced pain at short- and midterm follow-up when compared to standard total hip arthroplasty [5-8]. It has been argued that patient selection as well as intensive rehabilitation following surgery in this subgroup of patients may account for these excellent functional outcomes. For resurfacing, there have been various factors that have been shown to influence successful outcomes following surgery and rehabilitation. For example, it has been suggested that factors such as pre-operative level of activity [9], obesity [10], and gender [11] may affect the outcome. Additionally, patient selection and proper surgical technique is important in avoiding more common complications with this procedure such as femoral neck fracture, and femoral or acetabular component loosening. Although multiple 
studies have analyzed the effect of rehabilitation on conventional total knee or hip arthroplasty $[12,13]$, there are a limited number of reports that have addressed the influence of patient compliance and the level of commitment to rehabilitation on clinical outcome of hip resurfacing arthroplasty $[14,15]$.

The primary purpose of this study was to assess whether there is any correlation between patient commitment to rehabilitation and their clinical outcomes. The specific questions asked were: 1 ) Does patient rehabilitation effort correlate with clinical outcome and patient satisfaction?; 2) Do patient characteristics (preoperative diagnosis, gender, body mass index (BMI), age) influence whether a patient is committed to their rehabilitation?; and 3) What additional rehabilitation methods were required for patients who failed initial rehabilitation efforts?

\section{Methods}

A cross-sectional survey was utilized at our hospital to collect information regarding the level of commitment to rehabilitation following hip resurfacing from a series of patients who presented at the authors' center for a scheduled clinical follow-up visit. Completed surveys were received from 147 resurfacing patients (108 men and 39 women). The patients had a mean age of 56 years (range, 20 to 77 years) and a mean body mass index of $28 \mathrm{~kg} / \mathrm{m}^{2}$ (range, 18 to $53 \mathrm{~kg} / \mathrm{m}^{2}$ ). The men had a mean age of 57 years (range, 37 to 77 years) and a mean body mass index of $29 \mathrm{~kg} / \mathrm{m}^{2}$ (range, 21 to $53 \mathrm{~kg} / \mathrm{m}^{2}$ ), whereas the women had a mean age of 54 years (range, 20 to 69 years) and a mean body mass index of $26 \mathrm{~kg} / \mathrm{m}^{2}$ (range, 18 to $39 \mathrm{~kg} / \mathrm{m}^{2}$ ). There were 43 patients who were over 60 years of age and 30 patients who had a body mass index over $30 \mathrm{~kg} / \mathrm{m}^{2}$. There were 12 patients who had a preoperative diagnosis of osteonecrosis with all other patients having pain and dysfunction associated with advanced primary osteoarthritis. All patients were part of a Food and Drug Administration (FDA)-approved Investigational Device Exemption (IDE) prospective, multi-center, clinical trial.

There were a number of criteria that a patient had to meet to be considered a candidate for metal-on-metal resurfacing hip arthroplasty. Patients were all skeletally mature or at least 18 years old and had to be clinically qualified for a standard total hip arthroplasty based on medical history. Patients who were pregnant, had active human immunodeficiency virus or hepatitis infection, or had a neuromuscular or neurosensory deficiency that might adversely affect gait or weight bearing were not considered for this procedure. Additionally, if a patient had any documented allergy to cobalt, chromium, or molybdenum, they were contraindicated. Patients who had a revision to a standard total hip arthroplasty prior to the final follow-up of this study were not included.

All resurfacing procedures were performed by a single surgeon (MAM) using an antero-lateral approach. The Conserve Plus ${ }^{\oplus}$ hip resurfacing system (Wright Medical Technologies, Arlington, Tennessee) was used for all of the procedures. Standard equipment was used with the femoral head component sizes ranging from 38 to $52 \mathrm{~mm}$. The acetabular components were inserted in a press-fit manner after under-reaming by $1 \mathrm{~mm}$ and all femoral components were cemented.

A specific postoperative rehabilitation protocol was used for the IDE study, irrespective of patient age or body mass index. Patients progressed from $20 \%$ weightbearing for the first 5 to 6 weeks using crutches or a walker, followed by $50 \%$ weightbearing using a cane or crutch in the contralateral hand until 10 weeks, at which time full weightbearing was allowed. Inpatient physical therapy consisted of gait training, low-intensity isometrics, and isotonic exercises of the hip and knee extensors, as well as ankle pumps. Patients were encouraged to maintain hip precautions, which include no flexion past $90^{\circ}$, no adduction past midline, and no hip extension past $0^{\circ}$ for ten weeks. Patients were also encouraged to avoid rotation and avoid side-lying active hip abduction. All patients were allowed to weight-bear as tolerated with the aid of a walker or two crutches. Patients continued this program for 6 weeks from the date of surgery. At the end of 6 weeks, patients were given a prescription for outpatient physical therapy. All patients reported similar conventional rehabilitation programs that included progressive resistive exercises of the lower extremity including hip extensors, abductors, knee extensors, and ankle exercises. Patients were encouraged and trained to move from bilateral to unilateral support, and the goal of physical therapy was to achieve ambulation without assistive devices by 10 weeks from the date of surgery.

The patients' rehabilitation progress was assessed as part of an expanded version of a previously reported assessment questionnaire (Figure 1) [16]. They were asked to respond to the question; "please rate your commitment to your rehabilitation program," using an eleven-point scale where zero was no effort and poor compliance with the therapy regimen and ten was high effort and 100\% compliance. The questionnaire also included a series of post-operative questions related to activity level, competitiveness, and satisfaction.

In addition to the rehabilitation questionnaire, standard clinical outcome measures were collected at a mean follow-up of 52 months (range, 24 to 90 months). Clinical assessments were made prior to surgery and at final follow-up utilizing the Harris hip objective rating 


\section{Check one box that best describes your current activity level:}

$\square$ 1. Wholly Inactive, dependent on others, and can not leave residence.

$\square$ 2. Mostly inactive or restricted to minimum activities of living.

$\square$ 3. Sometimes participates in mild activities, such as walking, limited house work and limited shopping.

$\square$ 4. Regularly Participates in mild activities

$\square$ 5. Sometimes participates in moderate activities such as swimming or could do unlimited housework or shopping.

$\square$ 6. Regularly participates in moderate activities.

$\square$ 7. Regularly participates in active events such as bicycling.

$\square$ 8. Regularly participates in active events, such as golf or bowling.

$\square$ 9. Sometimes participates in impact sports such as jogging, tennis, skiing, acrobatics, ballet, heavy labor or backpacking.

$\square$ 10. Regularly participates in impact sports.

Using the same scale, ideally how active would you like to be?
$\square 1$.
$\square 2$.
$\square 3$.
$\square 4$.
$\square 5$.
$\square 6$.
$\square 7 . \quad \square 8$.
$\square 9$.
$\square 10$.

Physcial Activity Participation (Please list all activities you participate in following surgery)

Examples include: Gardening, Walking, Aerobics, Dancing, Road Biking, Stationary Biking, Jogging, Swimming, Football, Singes Tennis etc

\begin{tabular}{|c|c|c|}
\hline Activity & $\begin{array}{c}\text { Average } \\
\text { Frequency }\end{array}$ & \multicolumn{1}{c|}{ Average Duration } \\
\hline & Times/Week & \multicolumn{1}{|c|}{ Hours per Each Session } \\
\hline EXAMPLE \#1 Doubles Tennis & 7 & $\square<1 / 2$ hour $\square 1 / 2$ hour $\square 1$ hour $\square 2$ hours $\square 3$ hours $\square>3$ hours \\
\hline EXAMPLE \#2 Downhill Skiing & 6 X/year & $\square<1 / 2$ hour $\square 1 / 2$ hour $\square 1$ hour $\quad$ 2 hours $\square 3$ hours $\square>3$ hours \\
\hline & & $\square<1 / 2$ hour $\square 1 / 2$ hour $\square 1$ hour $\square 2$ hours $\square 3$ hours $\square>3$ hours \\
\hline & & $\square<1 / 2$ hour $\square 1 / 2$ hour $\square 1$ hour $\square 2$ hours $\square 3$ hours $\square>3$ hours \\
\hline & & $\square<1 / 2$ hour $\square 1 / 2$ hour $\square 1$ hour $\square 2$ hours $\square 3$ hours $\square>3$ hours \\
\hline & & $\square<1 / 2$ hour $\square 1 / 2$ hour $\square 1$ hour $\square 2$ hours $\square 3$ hours $\square>3$ hours \\
\hline & & $\square<1 / 2$ hour $\square 1 / 2$ hour $\square 1$ hour $\square 2$ hours $\square 3$ hours $\square>3$ hours \\
\hline & $\square<1 / 2$ hour $\square 1 / 2$ hour $\square 1$ hour $\square 2$ hours $\square 3$ hours $\square>3$ hours \\
\hline & & $\square<1 / 2$ hour $\square 1 / 2$ hour $\square 1$ hour $\square 2$ hours $\square 3$ hours $\square>3$ hours \\
\hline & $\square<1 / 2$ hour $\square 1 / 2$ hour $\square 1$ hour $\square 2$ hours $\square 3$ hours $\square>3$ hours \\
\hline & & $\square<1 / 2$ hour $\square 1 / 2$ hour $\square 1$ hour $\square 2$ hours $\square 3$ hours $\square>3$ hours \\
\hline
\end{tabular}

Circle a Number to answer each of the following:

How much did pain or stiffness limit your physical activity?

\begin{tabular}{|c|c|c|c|c|c|c|c|c|c|c|c|c|}
\hline No limitation & 0 & 1 & 2 & 3 & 4 & 5 & 6 & 7 & 8 & 9 & 10 & Severe Limitation \\
\hline \multicolumn{13}{|c|}{ How severe was your pain during the performed activities? } \\
\hline No Pain & 0 & 1 & 2 & 3 & 4 & 5 & 6 & 7 & 8 & 9 & 10 & Severe Pain \\
\hline \multicolumn{13}{|c|}{ Please rate your current satisfaction with your surgery. } \\
\hline Unsatisfied & 0 & 1 & 2 & 3 & 4 & 5 & 6 & 7 & 8 & 9 & 10 & Extremely Satisfiec \\
\hline
\end{tabular}

\section{Do you wear a BRACE ? $\quad \square$ No $\square$ Yes}

For how long have you worn it?

Have you attended PHYSICAL THERAPY? $\square$ No $\square$ Yes

How many sessions?

How many hours per session? Type:

\section{Was it helpful? $\quad \square$ No $\square$ Yes}

How many weeks did you attend?

How many times did you miss a scheduled session?

Are you currently on worker's compensation? $\square$ No $\square$ Yes

Please rate your commitment to your rehabilitation program.
Low Priority
1
23
45

0

Figure 1 Activity and rehabilitation questionnaire. Patients completed this one page questionnaire polling their activity levels and rehabilitation course. 
system [17]. Functional capability was also assessed at final follow-up using the SF-12 Health Survey and the eleven-point satisfaction score previously described [18]. No surviving patients had any evidence of component loosening or progressive radiolucencies during annual follow-up evaluations which were part of the FDA IDE study protocol. Two patients were revised to a total hip arthroplasty over the follow-up period. One patient underwent revision for a periprosthetic infection eight months following the resurfacing procedure. The second patient was revised at an outside institution for a femoral neck fracture that occurred secondary to a traumatic event four years following the index arthroplasty. Both cases were believed to be unrelated to the rehabilitation procedures.

\section{Statistical Analysis}

All data was collected using a Microsoft Access Database (Microsoft Corporation, Redmond, Washington). Data was exported to SPSS version 13.0 software (SPSS Incorporated, Chicago, Illinois) for statistical analyses. All statistical comparisons were conducted using 95\% confidence intervals where a p-value of less than 0.05 was considered significant. For each of the primary questions the following statistics were assessed: 1) Linear regression analysis and Pearson's coefficient were used to determine whether there was any correlation between the rehabilitation commitment scores and any of the outcome measures. A multivariate regression model was used to assess the influence of other factors including age, body mass index, medical comorbidities, diagnoses, and gender; 2) Multivariate regression analysis was used to assess the correlation of various factors with the level of commitment; 3) A Mann-Whitney Rank Sum test was used to compare the outcome scores between various patient populations. These results are shown in Table 1.

\section{Results}

Overall, the level of commitment to rehabilitation was shown to predict each of the outcome measures assessed: SF-12 Mental Component Score $(r=0.27$; $\mathrm{p}<0.001)$, SF-12 Physical Component Score $(r=0.21$; $\mathrm{p}<0.001)$, Harris Hip score $(\mathrm{r}=0.23)$, and satisfaction $\operatorname{score}(\mathrm{r}=0.35 ; \mathrm{p}<0.001)$. These correlations remained statistically significant in the multivariate regression model when controlling for age, body mass index, medical comorbidities, diagnosis, and gender. The overall mean rehabilitation commitment score was 8 points (range, 0 to 10 points). The mean Harris Hip score improved from 56 points (range, 27 to 78 points) prior to surgery to 92 points (range, 58 to 100 points) at final follow-up. At final follow-up, the mean SF-12 mental component score (MCS), physical component score (PCS), and patient satisfaction were 56,52 , and 9 points, respectively.

A comparison of the various clinical outcome measures between patients stratified by various demographic variables (for example, women versus men, high versus low body mass index) revealed a significantly lower mean pre-operative Harris hip score in women compared to men, a significantly lower mean satisfaction level in men compared to women, and a significantly lower mean Harris hip score at final follow-up in nonobese patients (see Table 1). However, these findings should be interpreted with caution as many of these variables may not be truly independent.

The multiple linear regression analysis assessing correlation of various demographic factors and commitment level showed that increasing body mass index had a negative correlation $(\mathrm{r}=0.32, \mathrm{p}=0.015$; see Figure 2$)$. The results of the analysis of both gender and age were not statistically significant in this model $(\mathrm{p}=0.889$ and 0.657 , respectively).

There were 5 patients who had continued muscle tightness at 3 or more months following surgery despite conventional rehabilitation efforts. Once muscle tightness was identified as an underlying cause of poor functional outcome, these patients were treated with customized therapy at our institution. Their rehabilitation sessions were scheduled 4 or 5 times a week for the first 2 to 3 weeks, and then 3 times a week until functional goals were achieved. Each therapy session included customized stretching consisting of 7 to 10 stretches for each affected muscle. The outpatient regimen included both individual exercises and activities that required the assistance of a family member. This protocol has been previously described as part of a standardized algorithm used at our institution [13].

\section{Discussion}

Total hip resurfacing arthroplasty may allow patients to have comparable function when compared to standard total hip arthroplasty [5-8]. The current levels of patient satisfaction and the timely return to full functional capabilities will potentially be improved with rehabilitation protocols that further develop the coordination between orthopaedic surgeons and other health professionals, as well as with the refinement of surgical techniques, pain management protocols, and appropriate patient expectations.

The limitations of this study include the short-term follow-up mean of 52 months and the still small numbers of patients $(n=147)$ that make this type of analysis difficult. In addition, following their initial in-patient rehabilitation program, not all patients received physical 
Table 1 Comparison of outcome scores between various stratified patient groups

\begin{tabular}{|c|c|c|c|c|c|c|c|c|c|c|}
\hline & $\begin{array}{c}\text { Pre- } \\
\text { operative } \\
\text { mean HHS } \\
\text { (range) }\end{array}$ & $\begin{array}{c}p \\
\text { value }\end{array}$ & $\begin{array}{c}\text { Mean HHS } \\
\text { at final follow-up } \\
\text { (range) }\end{array}$ & $\begin{array}{c}p \\
\text { value }\end{array}$ & $\begin{array}{c}\text { Mean } \\
\text { satisfaction } \\
\text { score } \\
\text { (range) }\end{array}$ & $\begin{array}{c}p \\
\text { value }\end{array}$ & $\begin{array}{c}\text { Mean SF-12 } \\
\text { MCS score } \\
\text { (range) }\end{array}$ & $\begin{array}{c}p \\
\text { value }\end{array}$ & $\begin{array}{l}\text { Mean SF-12 } \\
\text { PCS score } \\
\text { (range) }\end{array}$ & $\begin{array}{c}p \\
\text { value }\end{array}$ \\
\hline $\begin{array}{c}\text { Men }(n=108) \\
\text { Women }(n=39)\end{array}$ & $\begin{array}{l}58(27-78) \\
51(30-66)\end{array}$ & $<0.001$ & $\begin{array}{l}92(58-100) \\
92(69-100)\end{array}$ & 0.747 & $\begin{array}{l}8(0-10) \\
9(0-10)\end{array}$ & 0.008 & $\begin{array}{l}56(31-66) \\
57(38-64)\end{array}$ & 0.443 & $\begin{array}{l}32(32-60) \\
51(26-61)\end{array}$ & 0.170 \\
\hline $\begin{array}{c}\mathrm{BMI} \leq 30(\mathrm{n}=117) \\
\mathrm{BMI}>30(\mathrm{n}=30)\end{array}$ & $\begin{array}{l}55(33-70) \\
57(27-78)\end{array}$ & 0.689 & $\begin{array}{l}89(76-100) \\
92(58-100)\end{array}$ & 0.048 & $\begin{array}{l}8(0-10) \\
9(0-10)\end{array}$ & 0.070 & $\begin{array}{l}53(31-61) \\
57(38-66)\end{array}$ & 0.095 & $\begin{array}{l}51(32-60) \\
53(26-61)\end{array}$ & 0.068 \\
\hline $\begin{array}{l}\text { Age } \leq 60(n=104) \\
\text { Age }>60(n=43)\end{array}$ & $\begin{array}{l}56(27-78) \\
55(30-70)\end{array}$ & 0.617 & $\begin{array}{l}92(69-100) \\
91(58-100)\end{array}$ & 0.519 & $\begin{array}{l}9(0-10) \\
8(0-10)\end{array}$ & 0.698 & $\begin{array}{l}56(31-66) \\
57(39-64)\end{array}$ & 0.063 & $\begin{array}{l}53(26-61) \\
51(32-58)\end{array}$ & 0.524 \\
\hline $\begin{array}{l}\text { Osteoarthritis }(n=135) \\
\text { Osteonecrosis }(n=12)\end{array}$ & $\begin{array}{l}56(27-78) \\
58(32-75)\end{array}$ & 0.319 & $\begin{array}{l}91(58-100) \\
95(77-100)\end{array}$ & 0.120 & $\begin{array}{l}9(0-10) \\
10(7-10)\end{array}$ & 0.569 & $\begin{array}{l}56(31-66) \\
57(52-61)\end{array}$ & 0.816 & $\begin{array}{l}52(26-61) \\
55(47-57)\end{array}$ & 0.708 \\
\hline
\end{tabular}

HHS = Harris Hip Score; BMI = Body Mass Index; MCS = Mental Component Score; PCS = Physical Component Score

therapy at the same institution. However, all patients reported similar conventional rehabilitation protocols to make this less of a factor subject to bias.

Efforts have been made to develop standards regarding patient rehabilitation after conventional total hip arthroplasty. Youm et al [19] distributed a questionnaire to the 650 active members of the American Association of Hip and Knee Surgeons to evaluate surgeons' recommendations concerning postoperative rehabilitation and activity restriction. The authors used mean response scores to indicate a recommended standardized postoperative management protocol. Some of these recommendations included the use of an abduction pillow, a high toilet seat, a high chair for 6 weeks, as well as restricted hip flexion for 8 weeks. They also indicated that activities of daily living should be restricted until 5 weeks for driving, 6 weeks for sitting in an office chair, 7 weeks for carrying a brief case, 11 weeks for bending the hips and working on the hands and knees, and 12 weeks for climbing a ladder. Recommended activity levels were dependent on cemented or cementless stems. Nearly all respondents limited weight carrying to 10 pounds at 7 weeks for cemented stems and 8 weeks for cementless stems. While standardized rehabilitation techniques provide excellent results in most patients, the results of the present study suggest that there are some patients who may require additional customized protocols, especially younger patients. In addition, certain patients may need less rehabilitation.

In addition to establishing standards for the participation in functional activities and rehabilitation protocols, the use of a comprehensive, multidisciplinary, inpatient rehabilitation regimen has been shown by Dohnke et al [20] to be important in providing optimal outcomes after total hip arthroplasty. Their study evaluated the clinical outcome of 1,065 total hip arthroplasty patients for whom a coordinated multidisciplinary approach was followed. The inpatient rehabilitation began approximately 3 weeks (mean 22 days) after surgery, and the mean length of stay was approximately 23 days. Significant improvements in disability, pain, depressive symptoms, and ability to function independently were made postoperatively from the time of admission to discharge from the inpatient rehabilitation program.

While the present study suggests that current rehabilitation protocols for hip resurfacing patients yield satisfactory results, it remains unclear whether these programs are optimal. The protocols were originally designed for total hip arthroplasty patients who often are older and less active than many resurfacing patients. In the present study, there were three patients who discontinued rehabilitation after reaching all functional goals by 6 weeks post-operatively. Based on their excellent results and accelerated progress, they were cleared by their physical therapist (AB) and surgeon (MAM) from any additional prescribed rehabilitation. These results were similar to those reported by Crow et al. who found that a multimodal treatment approach allowed a 43 year-old man to return to sports activity following bilateral resurfacing [21]. Their rehabilitation approach focused on joint mobilization and the patient achieved approximately 90 degrees of hip flexion and 10 degrees of lateral rotation bilaterally by 3 months postoperatively. In another study, Newman et al. also 


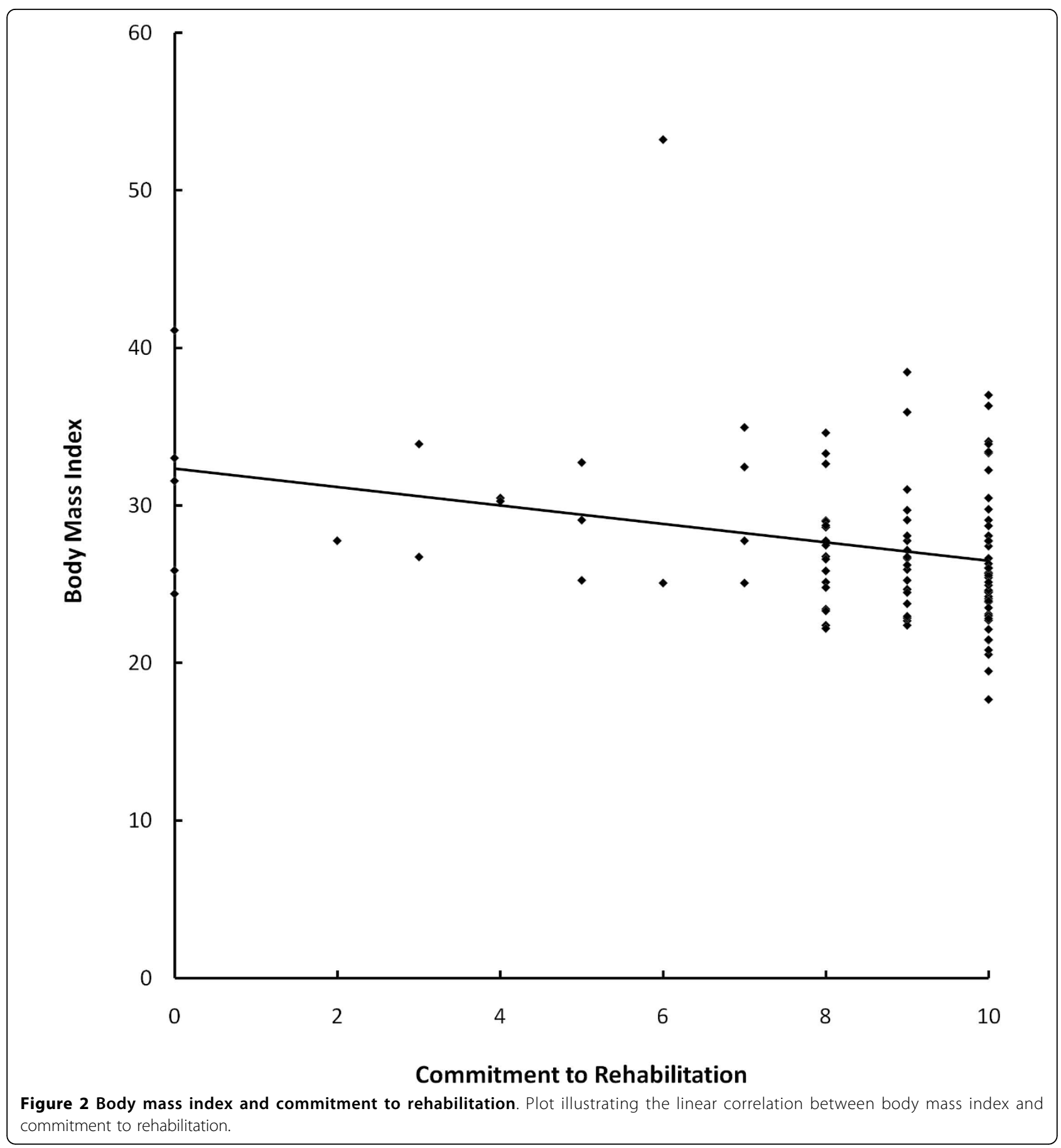

suggested that new rehabilitation standards may need to be adapted for resurfacing patients [15]. They assessed the outcomes of 126 hip resurfacing patients and reported excellent return to function following resurfacing with a mean Oxford Hip Score of 15 points and UCLA Activity Score of 7 points. However, they reported that approximately 1 out of 4 of the patients reported persistent pain with decreased strength and a reduced hip flexion at a mean of 95 degrees
(+/- 13 degrees). They concluded that the suboptimal recovery for some of their cohort may have been attributed to the rehabilitation protocols that were originally developed for standard total hip arthroplasty patients and not for their resurfacing arthroplasty counterparts.

Based partly on the results of this study, we currently we allow considerable variation from the previously described protocol for patients who are treated with a hip resurfacing arthroplasty, with progression based on 
the ability to achieve certain functional goals, rather than using only time since the index arthroplasty, which has most often been used in the past. Thus, some patients can be treated in an individual manner based on their ability to achieve certain functional milestones. Our current rehabilitation goal by five weeks following surgery is for the patient be able to ambulate pain free using single point cane in the opposite hand, go up and down the a flight of stairs, flex their hip to 90 degrees, and abduct to 30 degrees. We avoid strengthening exercises of the hip that are associated with pain, and specifically avoid side lying hip abduction strengthening early because of our anterolateral surgical approach. If patients achieve these well-defined goals earlier than 5 weeks we recommend faster progression to full range of motion, including rotation. We also progress patients to weight bearing as tolerated without the use of an assistive device, and place patients on progressive resistive exercises to improve hip abductor and extensor strength as long as resistive exercise does not cause pain. Accelerated, rather than time based, rehabilitation performed in this fashion may reduce the total time spent in rehabilitation for a number of patients. This preliminary study suggests that in general, a major commitment to rehabilitation should be made by patients to achieve the best clinical outcomes. In addition, patients who remain stiff or have difficulty progressing may require additional, tailored rehabilitation regimens. Conversely, patients who rapidly regain excellent function and a high activity level following surgery may be able to avoid further rehabilitation once certain goals are met. However, further investigation and multicenter studies need to be performed to confirm and refine these conclusions.

Based on the results of the current study, we suggest that increased body mass index may have a negative correlation with patient commitment to rehabilitation. Similar results were reported by Vincent et al. who examined whether obesity affected inpatient rehabilitation outcomes after total hip arthroplasty [22]. In their study, all patients completed an interdisciplinary inpatient rehabilitation program after surgery and were evaluated using functional independence measure scores, length of stay, efficiency scores (functional independence measure scores/length of stay), hospital charges, and discharge disposition location. Although functional independence measure scores improved from admission (mean of 25 points) to discharge (mean of 29.5 points) in all groups, the efficiency scores, length of stay functional independence measure scores, length of stay, and total charges were curvilinearly related to body mass index. They concluded that while elevated body mass index does not prevent functional gains in total hip arthroplasty patients during inpatient rehabilitation, increasing body mass index does influence efficiency, length of stay, and hospital charges in a negative manner. Furthermore, severely obese patients can achieve physical improvements, but at a lower efficiency and greater cost.

The use of a comprehensive activity and rehabilitation tool such as the one reported in the present study may allow surgeons to predict the postoperative recovery course for patients for hip resurfacing as well as other arthroplasty treatments, and allow for a tailoring of rehabilitation treatments. Additionally, it may assist surgeons in providing guidance regarding which treatment modality may be most appropriate for a given patient. Further study is necessary to better define these potential benefits.

\section{Conclusions}

The results of this study suggest that the level of commitment to rehabilitation influences outcomes with hip resurfacing, as we found that patients in our cohort who were more committed to their therapy returned to higher levels of functionality and satisfaction. The excellent early clinical outcomes following successful hip resurfacing in our cohort are similar to the results of other studies that have assessed modern hip resurfacing prostheses. We suggest that the importance of rehabilitation compliance should be stressed to resurfacing patients following surgery so that they can achieve maximal functional improvement and a healthier lifestyle.

\section{Author details}

Center for Joint Preservation and Replacement, Rubin Institute for Advanced Orthopedics, Sinai Hospital of Baltimore, Baltimore, Maryland, USA. ${ }^{2}$ Department of Orthopedic Surgery, Wake Forest University School of Medicine, Winston-Salem, North Carolina, USA. ${ }^{3}$ Rehabilitation Services, Rubin Institute for Advanced Orthopedics, Sinai Hospital of Baltimore, Baltimore, Maryland, USA.

\section{Authors' contributions}

DRM, AB, TMS, MAM, MGZ designed the study. DRM, MGZ, TMS collected the data. DRM, MGZ, TMS analyzed the data. DRM, MGZ, AB prepared the manuscript. AB, MGZ, TM, DRM, MAM ensured the accuracy of the data and analysis. All authors have read and approved the final manuscript.

\section{Competing interests}

External financial support was received specifically in support of the database used in this study from Wright Medical Technologies (Arlington, Tennessee). MAM is a consultant for Stryker Orthopaedics and Wright Medical Technologies.

None of the other authors have any financial or non-financial competing interests to disclose.

Received: 15 September 2009 Accepted: 22 March 2010

Published: 22 March 2010

\section{References}

1. Kurtz S, Ong K, Lau E, Mowat F, Halpern M: Projections of primary and revision hip and knee arthroplasty in the United States from 2005 to 2030. J Bone Joint Surg Am 2007, 89:780-785.

2. de Vreede $\mathrm{PL}$, Samson MM, van Meeteren NL, Duursma SA, Verhaar HJ: Functional-task exercise versus resistance strength exercise to improve 
daily function in older women: a randomized, controlled trial. $J \mathrm{Am}$ Geriatr Soc 2005, 53:2-10

3. Della Valle CJ, Nunley RM, Barrack RL: When is the right time to resurface? Orthopedics 2008, 31.

4. Mont MA, Schmalzried TP: Modern metal-on-metal hip resurfacing: important observations from the first ten years. J Bone Joint Surg Am 2008, 90(Suppl 3):3-11.

5. Treacy RB, McBryde CW, Pynsent PB: Birmingham hip resurfacing arthroplasty. A minimum follow-up of five years. J Bone Joint Surg Br 2005, 87:167-170.

6. Mont MA, Seyler TM, Marker DR, Marulanda GA, Delanois RE: Use of Metalon-Metal Total Hip Resurfacing for the Treatment of Osteonecrosis of the Femoral Head. J Bone Joint Surg Am 2006, 88(Suppl 3):90-97.

7. Vail TP, Mina CA, Yergler JD, Pietrobon R: Metal-on-metal hip resurfacing compares favorably with THA at 2 years followup. Clin Orthop Relat Res 2006, 453:123-131

8. Mont MA, Marker DR, Smith JM, Ulrich SD, McGrath MS: Resurfacing is Comparable to Total Hip Arthroplasty at Short-term Followup. Clin Orthop Relat Res 2008.

9. Roder C, Staub LP, Eggli S, Dietrich D, Busato A, Muller U: Influence of preoperative functional status on outcome after total hip arthroplasty. J Bone Joint Surg Am 2007, 89:11-17.

10. Le Duff MJ, Amstutz HC, Dorey FJ: Metal-on-metal hip resurfacing for obese patients. J Bone Joint Surg Am 2007, 89:2705-2711.

11. Marker DR, Seyler TM, Jinnah RH, Delanois RE, Ulrich SD, Mont MA: Femoral neck fractures after metal-on-metal total hip resurfacing: a prospective cohort study. J Arthroplasty 2007, 22:66-71.

12. Bhave A, Marker DR, Seyler TM, Ulrich SD, Plate JF, Mont MA: Functional problems and treatment solutions after total hip arthroplasty. J Arthroplasty 2007, 22:116-124.

13. Bhave A, Mont M, Tennis S, Nickey M, Starr R, Etienne G: Functional problems and treatment solutions after total hip and knee joint arthroplasty. J Bone Joint Surg Am 2005, 87(Suppl 2):9-21.

14. Hakkinen A, Borg H, Kautiainen $H$, Anttila E, Hakkinen K, Ylinen J, Kiviranta I: Muscle strength and range of movement deficits 1 year after hip resurfacing surgery using posterior approach. Disabil Rehabil 2009

15. Newman MA, Barker KL, Pandit H, Murray DW: Outcomes after metal-onmetal hip resurfacing: could we achieve better function? Arch Phys Med Rehabil 2008, 89:660-666.

16. Mont MA, Marker DR, Seyler TM, Gordon N, Hungerford DS, Jones LC: Knee Arthroplasties Have Similar Results in High- and Low-activity Patients. Clin Orthop Relat Res 2007.

17. Harris WH: Traumatic arthritis of the hip after dislocation and acetabular fractures: treatment by mold arthroplasty. An end-result study using a new method of result evaluation. J Bone Joint Surg Am 1969, 51:737-755.

18. Ware J Jr, Kosinski M, Keller SD: A 12-Item Short-Form Health Survey: construction of scales and preliminary tests of reliability and validity. Med Care 1996, 34:220-233.

19. Youm T, Maurer SG, Stuchin SA: Postoperative management after total hip and knee arthroplasty. J Arthroplasty 2005, 20:322-324.

20. Dohnke B, Knauper B, Muller-Fahrnow W: Perceived self-efficacy gained from, and health effects of, a rehabilitation program after hip joint replacement. Arthritis Rheum 2005, 53:585-592.

21. Crow JB, Gelfand B, Su EP: Use of Joint Mobilization in a Patient With Severely Restricted Hip Motion Following Bilateral Hip Resurfacing Arthroplasty. Phys Ther 2008

22. Vincent HK, Weng JP, Vincent KR: Effect of obesity on inpatient rehabilitation outcomes after total hip arthroplasty. Obesity (Silver Spring) 2007, 15:522-530.

doi:10.1186/1749-799X-5-20

Cite this article as: Marker et al: Does commitment to rehabilitation influence clinical outcome of total hip resurfacing arthroplasty? Journal of Orthopaedic Surgery and Research 2010 5:20.

\section{Submit your next manuscript to BioMed Central and take full advantage of:}

- Convenient online submission

- Thorough peer review

- No space constraints or color figure charges

- Immediate publication on acceptance

- Inclusion in PubMed, CAS, Scopus and Google Scholar

- Research which is freely available for redistribution

Submit your manuscript at www.biomedcentral.com/submit
Ciomed Central 